\title{
Diversidade genética entre acessos de cacau de fazendas e de banco de germoplasma na Bahia
}

\author{
Jeiza Botelho Leal(1), Leonardo Moreira dos Santos ${ }^{(1)}$, Crisliane Aparecida Pereira dos Santos ${ }^{(1)}$, \\ José Luís Pires ${ }^{(2)}$, Dário Ahnert ${ }^{(1)}$ e Ronan Xavier Corrêa ${ }^{(1)}$
}

\begin{abstract}
(1)Universidade Estadual de Santa Cruz, Rodovia Ilhéus-Itabuna, Km 16, CEP 45662-000 Ilhéus, BA. E-mail: jeizaleal@yahoo.com.br, leonardo001@bol.com.br, crislianeaparecida@hotmail.com, darioa@uesc.br, ronanxc@uesc.br (2)Centro de Pesquisas do Cacau, Seção de Genética, Caixa Postal 07, CEP 45600-970 Itabuna, BA. E-mail: joseluis@cepec.gov.br
\end{abstract}

\begin{abstract}
Resumo - O objetivo deste trabalho foi avaliar a diversidade genética de acessos de cacau, selecionados previamente como produtivos e resistentes à vassoura-de-bruxa na Bahia, e estudar suas inter-relações com genótipos no banco de germoplasma. Amostras de DNA de folhas dos 120 acessos, coletados em 17 fazendas de sete municípios do Sul da Bahia, foram amplificadas pela técnica de RAPD ("random amplified polymorphic DNA"). Os coeficientes de dissimilaridade genética, calculados pelo método de Jaccard a partir das bandas RAPD, permitiram evidenciar, pela análise de agrupamento, que a maioria das seleções das fazendas $(89,2 \%)$ agrupou-se com acessos do banco de germoplasma considerados representativos da diversidade de cacau (híbridos, trinitários, Scavinas, amazônicos e cacau-comum). As demais seleções distribuíram-se em outros sete grupos distintos. Há elevada diversidade genética entre as seleções das fazendas, e algumas delas devem ter-se originado de genitores não incluídos nesta análise. Esses materiais apresentam potencial para seleção de clones com maior diversidade para novos cruzamentos ou uso pelos agricultores.
\end{abstract}

Termos para indexação: Theobroma cacao, marcador molecular, melhoramento genético, vassoura-de-bruxa.

\section{Genetic diversity among farm and germplasm bank accessions of cacao in Bahia, Brazil}

\begin{abstract}
The objective of this work was to assess genetic diversity of farm cacao accessions, previously selected as productive and resistant to witch broom in Bahia, Brazil, and to study their interrelationship with reference genotypes on germplasm bank. DNA samples from 120 cacao accessions, collected on 17 farms in seven counties in Southern Bahia, were amplified by RAPD technique (random amplified polymorphic DNA). The coefficients of genetic dissimilarity, calculated from the RAPD bands by Jaccard method, allowed to show by cluster analysis that most farm selections (89.2\%) grouped with accessions from germplasm bank considered representatives of the cacao genetic diversity (hybrids, Trinitarian, Scavina, Amazon and common cacao). The other selections were distributed in seven distinct groups. There is high genetic diversity among farm selections, and some of them may have originated from other progenitors not included in this analysis. These materials present potential for clone selection with higher diversity for new crossings or direct use by agriculturists.
\end{abstract}

Index terms: Theobroma cacao, molecular markers, breeding, witch broom.

\section{Introdução}

A expansão da cacauicultura no Sul da Bahia foi realizada com plantios seminais, apesar de a tecnologia de plantio de cacau clonal por enxertia ser conhecida desde a década de 30 . Até 1960 predominou a utilização de sementes de acessos selecionados em diversas instituições de pesquisa ou nos plantios comerciais. No período de 1970 a 1990, os plantios a partir de sementes híbridas prevaleceram nessa região. $\mathrm{Na}$ primeira metade desse período, foram distribuídas pela Comissão Executiva do Plano da Lavoura Cacaueira (Ceplac) misturas de sementes oriundas de híbridos entre diversos clones, sem um controle total de progênie. Os híbridos com os clones Sca-06 e Sca-12 foram introduzidos na lavoura cacaueira no Sul da Bahia (Pinto \& Pires, 1998). Na segunda metade desse período, por causa das metas de expansão da lavoura cacaueira e, conseqüentemente, do aumento na demanda por sementes, foram utilizadas as obtidas de polinização aberta entre diferentes clones. Além disso, a mistura de híbridos foi reduzida a cruzamentos entre cacau-comum 
e acessos de cacau trinitários, selecionados em Trinidad, o que resultou em materiais muito suscetíveis à vassourade-bruxa (Yamada et al., 2001).

A partir de 1990, por causa do declínio da produção de cacau ocasionada pelo avanço da vassoura-de-bruxa, o plantio de clones resistentes foi adotado (Pereira, 2001). Muitos desses clones consistiram em seleções locais, feitas em condições de fazenda pelos agricultores, extensionistas e pesquisadores de instituições governamentais dessa região (Lopes et al., 2004). Apesar de essas seleções serem bastante difundidas na região, há poucas informações genéticas sobre elas. Sabe-se apenas que muitas delas originaram-se de poucas fontes de resistência (Yamada et al., 2003). Essas seleções devem ter-se originado de cerca de 18 genitores utilizados pela Ceplac, para a produção dos híbridos distribuídos aos agricultores (Faleiro et al., 2004b).

O cacau apresenta alta variabilidade genética, que permite a manipulação ampla da espécie pelo melhoramento (Dias, 2001). Os marcadores genéticos RAPD (Williams et al., 1990), sozinhos ou em associação com outros marcadores moleculares, têm sido utilizados nos estudos da variabilidade genética entre acessos provenientes de bancos internacionais de germoplasma de cacau (Lerceteau et al., 1997; Marita et al., 2001; Faleiro et al., 2004c; Sounigo et al., 2005) e dos bancos de germoplasmas e cultivares brasileiros (Dias, 2001; Yamada et al., 2001, 2003; Santos et al., 2005). Algumas seleções das fazendas no Sul da Bahia foram caracterizadas com base em marcadores RAPD (Faleiro et al., 2004b; Yamada et al., 2005) e microssatélites (Faleiro et al., 2004a). No entanto, esses trabalhos referemse a um número reduzido de seleções, inclusive menos de uma centena de materiais, os quais apresentaram, em sua maioria, relações estreitas com a série Scavina. Assim, torna-se necessário ampliar a amostragem, de forma representativa, dos municípios mais afetados pela vassoura-de-bruxa nos últimos 15 anos e levar em conta escolhas feitas pelos agricultores nessa amostragem. Além disso, essa escassez de informações sobre os cerca de 1.000 clones selecionados nas fazendas evidencia a necessidade de se buscarem novas e distintas fontes de resistência à vassoura-de-bruxa, para se ampliar a base genética do programa de melhoramento do cacau quanto à resistência a essa doença.

O objetivo deste trabalho foi analisar a diversidade genética de acessos de cacau, selecionados por agricultores como produtivos e resistentes à vassoura-de-bruxa, em fazendas afetadas por essa doença, e estudar as inter-relações dessas seleções com um conjunto de acessos do banco de germoplasma, representativo da ampla diversidade de cacau, citados como genitores de híbridos, distribuídos aos agricultores.

\section{Material e Métodos}

Foram analisados 120 acessos de cacau, dos quais 102 são seleções de fazenda e 18 são genótipos considerados no presente trabalho como referência da diversidade de cacau (Tabela 1). As 102 seleções de cacau resistentes à vassoura-de-bruxa foram obtidas por meio de um levantamento, realizado junto aos agricultores no período de fevereiro a abril de 2000, em 17 fazendas situadas em sete municípios do Sul da Bahia; as seleções foram identificadas com as iniciais do nome da fazenda ou de características da planta, seguidas pelo número de campo em fazenda. $\mathrm{O}$ critério de amostragem consistiu em solicitar aos agricultores a indicação de 5 a $10 \%$ dos clones que se mostraram resistentes à vassoura-de-bruxa, em pelo menos três anos de observação, nas condições das respectivas fazendas, e que, preferencialmente, tivessem apresentado as maiores produções de cacau. Os demais 18 acessos foram obtidos na coleção de germoplasma da Fazenda Almirante Cacau, Itajuípe, BA. Estes acessos são apresentados neste trabalho como de referência da diversidade, porque se encontram na lista de clones utilizados como genitores de híbridos distribuídos pela Ceplac, nas décadas de 1960 a 1980, na Bahia (Yamada \& Lopes, 1999; Yamada et al., 2001; Faleiro et al., 2004a). Além disso, eles são representativos dos grandes grupos genéticos de cacau, em que não estão presentes apenas os do tipo Criollo.

Duas folhas de cada planta foram coletadas em estágio intermediário de maturação e foram mantidas a $-80^{\circ} \mathrm{C}$ até o momento de sua utilização para extração de DNA, que foi realizada com $300 \mathrm{mg}$ de folha pelo método de CTAB (Doyle \& Doyle, 1990), com pequenas modificações (Freire et al., 2007). Amostras de DNA de cada planta foram amplificadas por RAPD (Williams et al., 1990), em condições de amplificação e eletroforese previamente padronizadas (Freire et al., 2007). Foram utilizados iniciadores decâmeros dos kits OPA, OPB, OPC, OPD, OPH, dos quais 20 iniciadores por kit, cujas sequiências encontram-se em Operon 
Molecules for Life (2005). Apenas aqueles que produziram bandas consideradas consistentes (nítidas a olho nu para pelo menos dois pesquisadores), quanto ao controle experimental, foram incluídos nas análises finais. Esse controle consistiu em se adicionar o DNA do clone ICS-1 (tomado ao acaso entre os materiais disponíveis) a cada 18 plantas, no total de seis repetições de DNA-controle, de modo que, em todos os lotes de reações e em cada gel, houvesse um mesmo DNA repetido; todo iniciador cujo padrão de bandas não se repetiu entre reações-controle foi descartado da análise.

As distâncias genéticas foram determinadas com base no complemento dos coeficientes de similaridade de Jaccard, com auxílio do programa Genes (Cruz, 2001), a partir de uma matriz de dados binários de presença, ausência e dado faltante, representados por 1,0 e 9 , respectivamente. As distâncias genéticas foram utilizadas para a análise de agrupamento, realizada com auxílio do programa SAS, pelo método do centróide e com base no sistema de escalonamento multidimensional - MDS (SAS Institute, 1988). O agrupamento foi demonstrado pela dispersão dos genótipos no espaço de três dimensões e pela lista de genótipos integrantes de cada grupo validado, com base nas estatísticas pseudo $\mathrm{F}$ e pseudo t (SAS Institute, 1988).

\section{Resultados e Discussão}

Dos 100 iniciadores testados, os 13 mais informativos e reprodutíveis foram utilizados para amplificar os 120 acessos de cacau: A1, A2, A12, A20, B5, B8, B11, C13, C16, D1, D10, D20 e H8. A utilização desse menor número é estratégia utilizada em estudos com cacau (Lerceteau et al., 1997) e outras espécies arbóreas (Heider et al., 2007). Entre as 91 bandas RAPD obtidas no presente trabalho, 61 foram monomórficas e 30 polimórficas - estas representam 33\%, o que corresponde a 2,3 bandas polimórficas por iniciador, o que é semelhante às 2,2 obtidas por Lerceteau et al. (1997) e menor do que as 3,5 obtidas por Marita et al. (2001), porém com qualidade satisfatória para as análises. Os 18 iniciadores selecionados por Lerceteau et al. (1997) geraram 67 bandas, das quais $40(59,7 \%)$ foram polimórficas, o que mostra nível de polimorfismo superior ao encontrado neste trabalho. Esta proporção de bandas polimórficas também varia entre espécies filogeneticamente relacionadas, como observado por Romeiras et al. (2006), que detectaram com o mesmo conjunto de 20 iniciadores RAPD as seguintes proporções: das 83 bandas amplificadas em Echium hypertropicum, 22 (26,5\%) foram polimórficas; das 115 bandas amplificadas em Echium stenosiphon,

Tabela 1. Código de identificação e quantidade $(\mathrm{Q})$ de acessos de cacau, selecionados como produtivos e resistentes à vassoura-de-bruxa, das coleções de germoplasma de fazendas localizadas em diferentes municípios do Sul da Bahia, e código de identificação, grupo genético e origem geográfica dos acessos da coleção de germoplasma da Fazenda Almirante Cacau, Itajuípe, BA.

\begin{tabular}{|c|c|c|c|c|c|c|}
\hline Código $^{(1)}$ & $\mathrm{Q}$ & Nome da fazenda & Município & Código $^{(2)}$ & Grupo $^{(3)}$ & Origem \\
\hline$\overline{\mathrm{C}}$ & 37 & Conjunto Camacã & Camacã & UF-613 & Tri & Costa Rica \\
\hline VBB & 5 & Brasil & Ilhéus & UF-667 & Tri & Costa Rica \\
\hline SP & 1 & São Pedro & Ilhéus & ICS-1 & Tri & Trinidad \\
\hline BVP & 1 & Banco da Vitória & Ilhéus & TSH-1188 & $\mathrm{Hib}$ & Trinidad \\
\hline $\mathrm{FC}$ & 2 & Convenção & Itabuna & TSH-516 & $\mathrm{Hib}$ & Trinidad \\
\hline $\mathrm{T}$ & 1 & Tararanga & Itajuípe & TSH-565 & $\mathrm{Hib}$ & Trinidad \\
\hline M & 1 & Massaranduba & Itajuípe & EET-397 & $\mathrm{Hib}$ & Equador \\
\hline SJ & 2 & São José & Itajuípe & EEG-29 & $\mathrm{Hib}$ & Brasil \\
\hline AL, VB & 2 & Almirante Cacau & Itajuípe & SIAL-70 & Comum & Brasil \\
\hline $\mathrm{OP}, \mathrm{BF}$ & 3 & Futurosa & Jussari & SIAL-169 & Comum & Brasil \\
\hline VT & 4 & N.Sr- ${ }^{\mathrm{a}}$ da Vitória & S.J. Vitória & Catongo & Comum & Brasil \\
\hline $\mathrm{PH}$ & 1 & Porto Híbrido & S.J. Vitória & Cepec-42 & Comum & Brasil \\
\hline SAF & 1 & Santo Antônio & Uruçuca & Q-7, Q-8 & Comum & Brasil \\
\hline SR & 4 & Santa Rosa & Uruçuca & Sca-6 & Sca & Peru \\
\hline FB & 25 & Brasileira & Uruçuca & Sca-12 & Sca & Peru \\
\hline AM & 3 & América & Uruçuca & $\mathrm{Pa}-300$ & Amaz & Peru \\
\hline $\mathrm{FL}$ & 9 & Leolinda & Uruçuca & IMC-67 & Amaz & Peru \\
\hline
\end{tabular}

${ }^{(1)}$ Código do grupo de acessos, atribuído às coleções de germoplasma de fazendas. (2)Código internacional adotado para os acessos da coleção de germoplasma da Fazenda Almirante Cacau, Itajuípe, BA; Q-7 e Q-8 referem-se a duas plantas de cacau-comum, coletadas nas quadras 7 e 8 da Fazenda Almirante Cacau, Itajuípe, BA. ${ }^{(3)}$ Tri: trinitário; Hib: híbrido; Comum: cacau-comum; Sca: Scavina; Amaz: amazônico. 
$85(73,9 \%)$ foram polimórficas. Embora o número de bandas polimórficas obtido neste trabalho tenha sido relativamente pequeno, os resultados obtidos com o RAPD são úteis para os pesquisadores da área, subsidiados pelos esforços de coletas e pela comparação com os exemplares de origem conhecida, armazenados nos bancos de germoplasma (Lerceteau et al., 1997), ou mesmo em populações naturais (Heider et al., 2007; Romeiras et al., 2007). Além disso, o coeficiente de variação das distâncias genéticas estabiliza entre 25 e 35 bandas polimórficas, em estudos de diversidade com cerca de 150 acessos de cacau (Lerceteau et al., 1997).

A distância genética média, entre cada acesso e o conjunto dos 18 acessos do banco de germoplasma, é maior do que entre cada acesso e o conjunto das 102 seleções das fazendas (Figura 1). Contudo, a amplitude de variação dos valores de distância genética entre as seleções (mínimo 0,04 entre os acessos FL-04 e FL-66; máximo 0,73 entre os acessos SR-03 e C-207) foi maior do que aquela observada entre os genótipos de referência (mínimo 0,16 entre os acessos Q7 e EEG-29; máximo 0,45 entre os acessos Sca-12 e SIAL-70), o que indica existir maior variabilidade entre as seleções do que entre os acessos do banco de germoplasma. Esses dados foram semelhantes àqueles obtidos por Santos et al. (2005), entre clones da série CEPEC (mínimo de 0,18; máximo de 0,76). Entre as 102 seleções, foram observadas, em pelo menos três anos, 55 que possuem variação quanto à produção (Monteiro et al., 2003). Portanto, a variabilidade genética detectada por meio dos marcadores RAPD, no presente trabalho, e pelas análises da característica produção, comprovam que essas seleções podem ser úteis para o melhoramento do cacau a partir de seleções locais.

Os 120 acessos de cacau foram codificados quanto à origem e projetados no plano tridimensional, com base nos coeficientes de dissimilaridade genética (Figura 2). Observou-se que a maioria dos acessos provenientes das fazendas ficou distribuída entre os acessos de referência do banco de germoplasma. Contudo, a projeção das plantas no plano tridimensional também evidenciou que, enquanto as seleções ocuparam seis dos nove quadrantes formados pelas dimensões 1 e 2, os acessos de referência ocuparam apenas três quadrantes, e os representantes do cacau-comum concentraram-se em um quadrante marginal, em que ocorreram poucas seleções. Quando confrontados em um conjunto de 270 acessos de bancos de germoplasma internacionais, esses genótipos de referência mostraram-se distantes e, portanto, representam uma diversidade significativa em cacau (Marita et al., 2001). Por sua vez, os dados do presente trabalho comprovam que as seleções de fazenda apresentaram diversidade genética mais ampla do que os 18 genótipos controle. Considerando-se esses controles, supõe-se que os materiais de fazenda representativos dos diferentes agrupamentos sejam adequados para utilização em programas de melhoramento do cacau, com o fim de se incorporar maior variabilidade genética entre os materiais.

$\mathrm{Na}$ análise de agrupamento, a validação dos diferentes números de grupos, pelas estatísticas pseudo $\mathrm{F}$ e pseudo t, possibilitou adotar a distinção dos genótipos em quatro grupos e dez subgrupos de diversidade (Tabela 2). Dos quatro grupos formados, o grupo I incluiu cinco subgrupos: I.1 - os clones Sca-06 e Sca-12, os trinitários representados por UF-667 e ICS-01, os híbridos que incluem Sca na genealogia, representados por TSH-516, TSH-565, TSH-1188, CEPEC-42, EET-397 e 83 seleções de fazenda $(81,4 \%)$; I. 2 - o cacau-comum representado por SIAL-70, SIAL-169, Catongo, Q-7, Q-8, EEG-29, o alto-amazônico IMC-67, o trinitário UF-613 e seis seleções de fazendas (5,9\%); I.3, I.4, I.5 - cada um com apenas uma seleção de fazenda. As seleções do subgrupo I.1 provavelmente descendem de Sca-6, ICS-01 ou algum clone destes derivados como os da série TSH, uma vez que esses materiais são

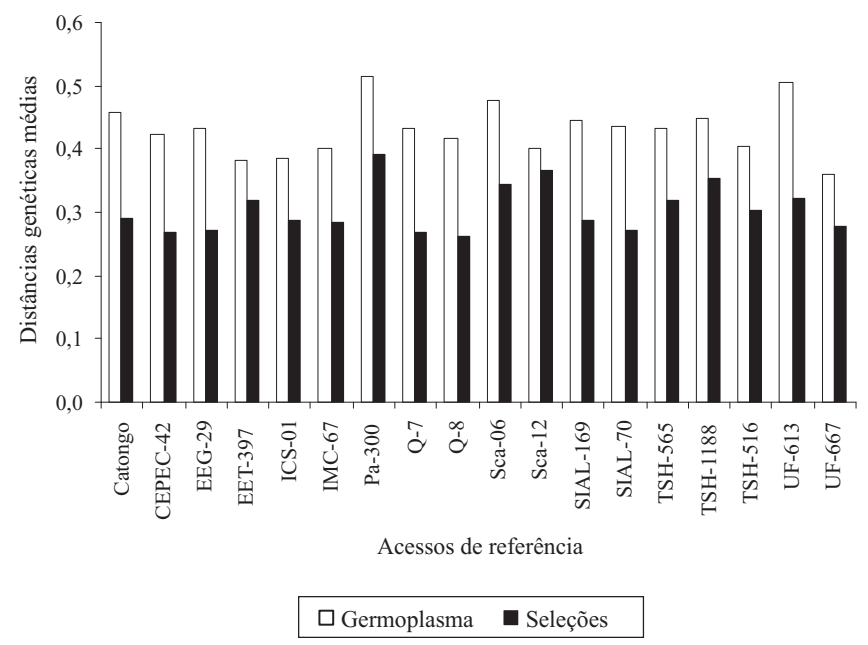

Figura 1. Comparações entre a distância genética de cada acesso de referência (Germoplasma) e as distâncias genéticas médias do grupo de acessos das fazendas (Seleções) e do grupo de acessos de referência. 
relatados como genitores utilizados na produção de híbridos pela Ceplac (Pinto \& Pires, 1998; Santos et al., 2005).
O grupo II foi constituído por nove acessos, distribuídos em três subgrupos: II.1 - cinco seleções de fazenda; II. 2 - o Pa-300 e duas seleções de fazenda (2\%);

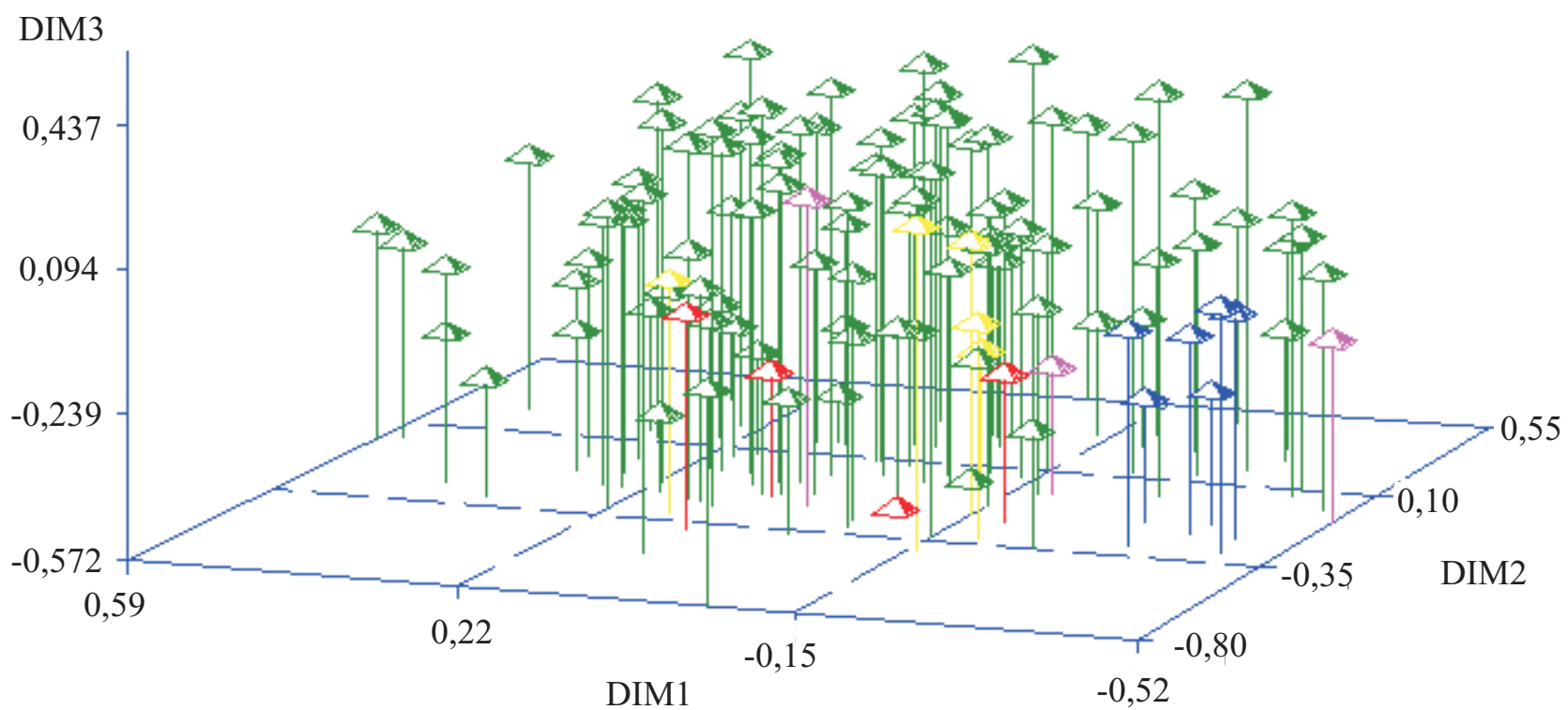

Figura 2. Dispersão dos 120 acessos de cacau, com base nos coeficientes de diversidade genética, pelo sistema de escalonamento multidimensional e pela codificação dos acessos por cores, segundo os grupos genéticos de clones. Verde: seleções das fazendas; rosa: trinitários (UF-613, ICS-1, UF-667); amarelo: híbridos (TSH-1188, TSH-516, TSH-565, EET-397 e EEG-29); azul: representantes do cacau-comum (SIAL 70, SIAL-169, Catongo, Cepec-42, Q-7 e Q-8); vermelho: Scavinas (Sca-6 e Sca-12) e amazônicos (PA-300 e IMC-67). Os eixos representam as três dimensões multidimensionais (DIM).

Tabela 2. Agrupamento dos 120 acessos de cacau, pelo método hierárquico centróide, em que se evidenciam quatro grupos e dez subgrupos de subdivisão significativa da diversidade genética, calculada pelo método de Jaccard com base em marcadores RAPD.

\begin{tabular}{|c|c|c|}
\hline Grupo & Subgrupo & Acessos \\
\hline \multirow[t]{5}{*}{ I } & I.1 & $\begin{array}{l}\text { AL-05, AM-01, AM-03, BF-01, C-03, C-83, C-56, C-08, C-54, C-207, C-70, C-104, C-80, C-232, C10, C-99, } \\
\text { C-217, C-92, C-101, C-15, C-218, C-97, C-237, C-208, C-48, C-107, C-219, C-106, C-231, C-235, C-74, C-232, } \\
\text { C-100, C-16, C-95, C-220, C-96, C(ICS-01)f, FB-1148, FB-60, FB-33, FB-1139, FB-19, FB-26, FB-48, FB-31, } \\
\text { FB-28, FB-76, FB-55, FB-206, FB-1150, FB-30, FB-43, FB-1151, FB-16, FB-24, FB-72, FB-1149, FB-34, } \\
\text { FB-38, FC-1, FC-1154, FL-70, FL-62, FL-73, FL-77, FL-45, M-05, OP-01, PH-16, SJ-01, SJ-02, SR-01, SR-04, } \\
\text { T-10, VB-1139, VBB-01, VBB-05, VBB-08, VT-05, VT-09, VT-10, VT-18, CEPEC-422 }{ }^{(1)}, \text { EET-397 } \\
\text { ICS-01 }^{(1)}, \text { Sca-12 }^{(1)}, \text { Sca-06 }^{(1)}, \text { TSH-516 }^{(1)}, \text { TSH- } 1188^{(1)}, \text { TSH-565 }^{(1)}, \text { UF-667 }\end{array}$ \\
\hline & I.2 & $\begin{array}{l}\text { BVP-01, FL-60, FL-66, FL-04, SAF-01, SR-05, Catongo } \\
\text { SIAL-70 }^{(1)}, \text { IMC- }^{(1)} 7^{(1)}, \text { EEG-613 }^{(1)}\end{array}$ \\
\hline & I.3 & AM-02 \\
\hline & I.4 & $\mathrm{C}-239$ \\
\hline & I.5 & C-108 \\
\hline \multirow[t]{3}{*}{ II } & II.1 & FB-1142, FB-1144, SP-304, SR-03, VBB-1142 \\
\hline & II.2 & FB-39, VBB-07, $\mathrm{Pa}-300^{(1)}$ \\
\hline & II.3 & FL-16 \\
\hline III & III.1 & C-47 \\
\hline IV & IV.1 & OP-03 \\
\hline
\end{tabular}

${ }^{(1) G e n o ́ t i p o s ~ d e ~ r e f e r e ̂ n c i a, ~ p r o v e n i e n t e s ~ d a ~ c o l e c ̧ a ̃ o ~ d e ~ g e r m o p l a s m a ~ d a ~ F a z e n d a ~ A l m i r a n t e ~ C a c a u, ~ I t a j u i ́ p e, ~ B A . ~}$ 
II.3 - com apenas uma seleção. Essa tendência de agrupamento de um grande número de seleções, associadas a Scavina, e um pequeno número de seleções com genótipos da série Pa, também foi verificada por Yamada \& Lopes (1999), em análise de paternidade de cacau com base em dados isoenzimáticos. $\mathrm{Na}$ análise de diversidade genética de diferentes genitores, utilizados pela Ceplac na década de 60 para produção de híbridos (Pinto \& Pires, 1998), verificou-se que Sca e Pa estão em grupos distintos (Yamada et al., 2001). Na análise de 270 acessos internacionais de bancos de germoplasma, os cinco acessos Pa ficaram distantes dos dois acessos de Scavina (Marita et al., 2001).

Os grupos III e IV foram constituídos pelos subgrupos III.1 e IV.1, que possuem apenas os genótipos C-47 e OP-03, respectivamente. Estes grupos e os subgrupos I.3, I.4, I.5, II.1 e II.3 correspondem a 11 genótipos $(10,1 \%)$ que não se agruparam com nenhum genótipo de referência. Esses subgrupos são indicativos da existência de genitores diferentes daqueles que foram tomados como referência neste trabalho, incluindo-se Scavina, ICS e seus híbridos.

Os subgrupos I.1, I.2 e II.2, que incluíram acessos entre os 18 considerados neste trabalho como potenciais genitores e genótipos de referência, mostraram-se consistentes com observações anteriores, baseadas em análises por RAPD: Yamada et al. (2001) demonstraram que os potenciais genitores são clones geneticamente diversos, e que os Sca, Pa e IMC ficaram em ramos distintos nos dendrogramas; Marita et al. (2001) demonstraram que os Sca ficaram em quadrantes distintos dos demais clones, na análise de coordenadas principais de cerca de 270 acessos internacionais de cacau; Sounigo et al. (2005) evidenciaram que populações de Sca, Pa, IMC, ICS e UF são estabelecidas como ramos significativamente distintos, em dendrogramas relativos a 26 populações de cacau silvestres e cultivadas. Está consistente com a história genealógica a observação de que esses potenciais genitores classificados como trinitários, cacau-comum, amazônico e Scavinas têm diferentes origens geográficas e que foram, em parte, utilizados para gerar a mistura de híbridos para os plantios entre 1960 e 1990 (Dias, 2001). Isso permite inferir que os genótipos encontrados nas fazendas do Sul da Bahia apresentam uma combinação genética desses materiais. No entanto, há algumas dessas seleções de fazenda que estão distantes desse grande grupo, que tem relações genealógicas com Scavina, bem como distantes do grupo formado pelos representantes de cacau-comum.

Os 120 acessos de cacau foram codificados quanto aos subgrupos definidos pelo agrupamento e projetados no plano tridimensional, com base nos coeficientes de dissimilaridade genética (Figura 3). Observou-se mais

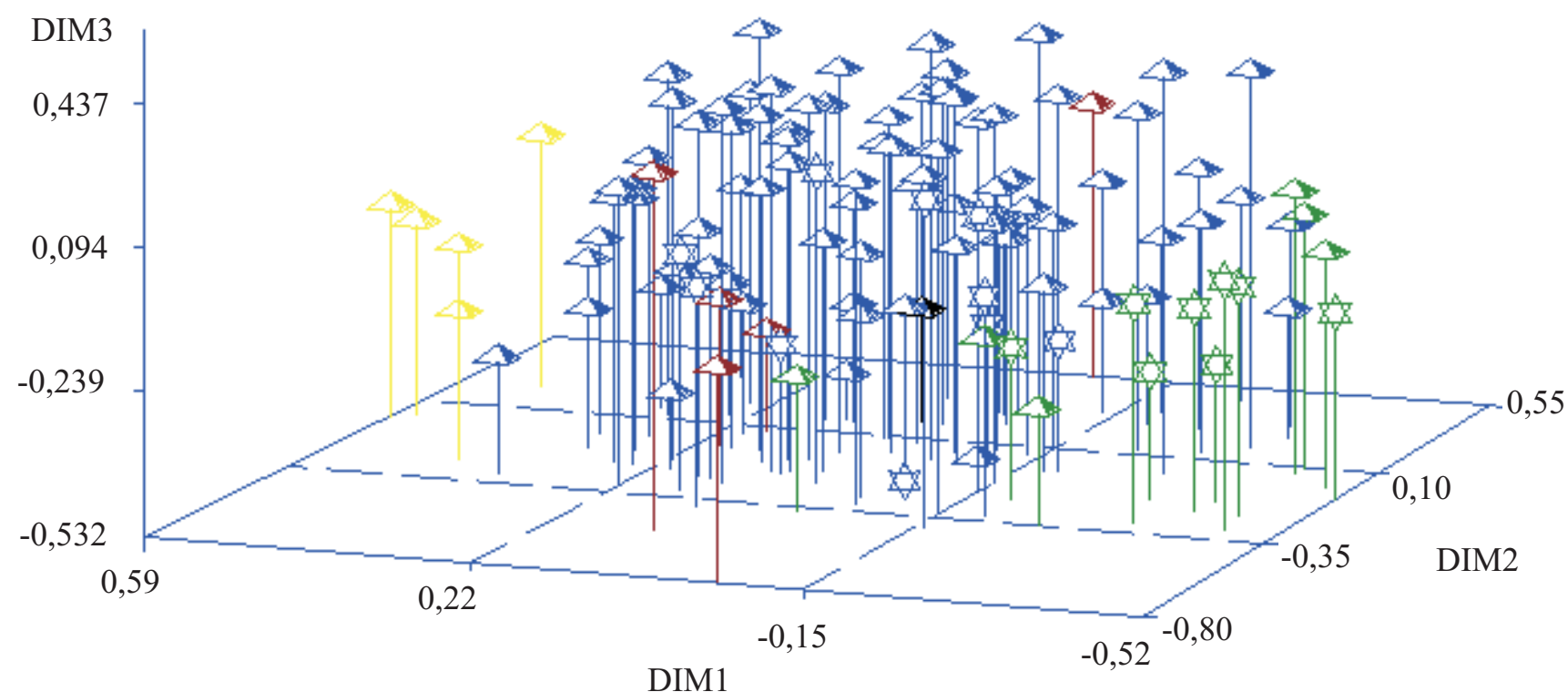

Figura 3. Dispersão multidimensional de 102 seleções de cacau (triângulos) e 18 acessos de referência (estrelas, exceto PA-300, que é o triângulo preto), codificadas por cores segundo os subgrupos descritos na Tabela 2: I.1, azul; II.1, amarelo; I.2, verde; II.2, preto (um genitor) e verde (duas seleções); I.3, I.4, I.5, II.3, III.1, IV.1, formados cada um por uma planta, marrom. Os eixos representam as três dimensões multidimensionais (DIM). 
claramente que, embora a maioria dos acessos provenientes das fazendas esteja disposta entre os acessos de referência, estes estão presentes em apenas três dos dez subgrupos. Os clones Sca-6 e Sca-12 apresentaram-se relativamente distantes dos clones TSH-1188 e TSH-565, bem como de EEG-29, Cepec-42 e ICS-01, quando comparados com 270 acessos de cacau de 13 países produtores, por meio de marcadores RAPD (Marita et al., 2001). Ao se compararem as seleções das fazendas com estudos de diversidade de materiais de múltiplas origens, os dados indicam que as seleções de fazenda possuem diversidade alta, relativamente aos materiais controle sabidamente representativos da diversidade dos grandes grupos de cacau. Portanto, as seleções de fazendas são promissoras para programas de melhoramento, uma vez que aqueles genótipos mais distantes entre si poderão constituir fontes de diferentes alelos, para combinação e formação de cultivares agronomicamente superiores. Assim, as análises moleculares são uma ferramenta auxiliar na orientação de novas estratégias de cruzamentos e diversificação de materiais, para minimizar os riscos de quebra da resistência a doenças pelos cultivos nas regiões de alta pressão de inóculo. Supõe-se que os materiais muito relacionados entre si devem ter os mesmos alelos de resistência à vassourade-bruxa e a outras doenças.

\section{Conclusões}

1. Os acessos de cacau selecionados pelos agricultores como produtivos e resistentes à vassoura-de-bruxa, nas plantações comerciais da Bahia, apresentam ampla diversidade genética, quando comparados pela técnica de RAPD.

2. A diversidade genética dos acessos de cacau selecionados pelos agricultores como produtivos e resistentes à vassoura-de-bruxa nas plantações comerciais da Bahia é mais ampla do que aquela encontrada entre os genótipos do banco de germoplasma, correspondentes aos supostos genitores utilizados para produzir as variedades híbridas de cacau.

\section{Agradecimentos}

Ao Conselho Nacional de Desenvolvimento Científico e Tecnológico, à Coordenação de Aperfeiçoamento de Pessoal de Nível Superior, à Universidade Estadual de Santa Cruz (UESC) e ao Programa de Pós-Graduação em Genética e Biologia Molecular da UESC, por concessão de bolsas; à Fundação de Amparo à Pesquisa do Estado da Bahia e à UESC, pelo apoio financeiro; ao pesquisador Alan Vilella Pomella (MARS, Inc.) e ao Técnico Mariosvaldo Morais Macêdo (Ceplac), pelo fornecimento de parte das amostras de cacau.

\section{Referências}

CRUZ, C.D. Programa Genes: aplicativo computacional em genética e estatística: versão 2001. Viçosa: UFV, 2001. 648p.

DIAS, L.A.S. Melhoramento genético do cacaueiro. Viçosa: Funape, 2001. 578p.

DOYLE, J.J.; DOYLE, J.L. Isolation of plant DNA from fresh tissue. Focus, v.12, p.13-15, 1990.

FALEIRO, A.S.G.; FALEIRO, F.G.; LOPES, U.V.; MELO, G.R.P.; MONTEIRO, W.R.; YAMADA, M.M.; BAHIA, R.C.S.; CORREAA, R.X. Variability in cacao selected by producers for resistance to witches' broom based on microsatellite markers. Crop Breeding and Applied Biotechnology, v.4, p.290-297, 2004a.

FALEIRO, F.G.; LOPES, U.V.; YAMADA, M.M.; MELO, G.R.P.; MONTEIRO, W.R.; PIRES, J.L.; ROCHA, J.B.; BAHIA, R.C.S.; GOMES, L.M.C.; ARAÚJO, I.S.; FALEIRO, A.S.G. Genetic diversity of cacao accessions selected for resistance to witches' broom disease based on RAPD markers. Crop Breeding and Applied Biotechnology, v.4, p.12-17, 2004b.

FALEIRO, F.G.; PIRES, J.L.; MONTEIRO, W.R.; LOPES, U.V.; YAMADA, M.M.; PIEDRA, A.G.; MOURA, A.D.; ARÉVALOGARDINI, E.A.; MARQUES, J.R.B.; GRAMACHO, K.P.; FALEIRO, A.S.G.; SANTOS, M.C.M. Variability in cacao accessions from the Brazilian, Ecuadorian, and Peruvian Amazons based on molecular markers. Crop Breeding and Applied Biotechnology, v.4, p.227-233, 2004c.

FREIRE, J.M.; PIÑA-RODRIGUES, F.C.M.; LIMA, E.R.; SODRÉ, S.R.C.; CORRÊA, R.X. Estrutura genética de populações de Schizolobium parahyba (Vell.) Blake (guapuruvu) por meio de marcadores RAPD. Scientia Forestalis, v.74, p.27-35, 2007.

HEIDER, B.; ANDERSSON, M.S.; SCHULTZE-KRAFT, R. RAPD variation among North Vietnamese Flemingia macrophylla (Willd.) Kuntze ex Merr. Biodiversity and Conservation, v.16, p.1617-1631, 2007.

LERCETEAU, E.; ROBERT, T.; PÉRTIARD, V.; CROUZILLAT, D. Evaluation of the extent of genetic variability among Theobroma cacao accessions using RAPD and RFLP markers. Theoretical and Applied Genetics, v.95, p.10-19, 1997.

LOPES, U.V.; MONTEIRO, W.R.; PIRES, J.L.; ROCHA, J.B., PINTO, L.R.M. On farm selection for witches' broom resistance in Bahia, Brazil: a historical retrospective. Agrotrópica, v.16, p.61-66, 2004.

MARITA, J.M.; NIENHUIS, J.; PIRES, J.L.; AITKEN, W.M. Analysis of genetic diversity in Theobroma cacao with emphasis on witches' broom disease resistance. Crop Science, v.41, p.1305-1316, 2001. 
MONTEIRO, E.M.L.; PINTO, R.M.C.; CORRÊA, R.X.; MACÊDO, M.M.; AHNERT, D. Variabilidade em clones de cacaueiros resistentes à vassoura-de-bruxa com base em caracteres agronômicos. In: CONGRESSO BRASILEIRO DE MELHORAMENTO DE PLANTAS, 3., 2003, Porto Seguro. Anais. Porto Seguro: Sociedade Brasileira de Melhoramento de Plantas, 2003. (CD-ROOM).

OPERON MOLECULES FOR LIFE. RAPD 10mer Kits. Disponível em: <http://www.operon.com>. Acesso em: 15 fev. 2005.

PEREIRA, A.B. Melhoramento clonal. In: DIAS, L.A.S. (Ed.). Melhoramento genético do cacaueiro. Viçosa: Funape, 2001. p.361-384.

PINTO, L.R.M.; PIRES, J.L. Seleção de plantas de cacau resistentes à vassoura-de-bruxa. Ilhéus: Ceplac, Cepec, 1998. 35p. (Boletim Técnico, 181).

ROMEIRAS, M.M.; COTRIM, H.C.; DUARTE, M.C.; PAIS, M.S. Genetic diversity of three endangered species of Echium L. (Boraginaceae) endemic to Cape Verde Islands. Biodiversity and Conservation, v.16, p.547-566, 2007.

SANTOS, R.C.; PIRES, J.L.; LOPES, U.V.; GRAMACHO, C.P.G.; FLORES, A.B.; BAHIA, R.C.S.; RAMOS, H.C.C.; CORREAA, R.X.; AHNERT, D. Assessment of genetic diversity on a sample of cocoa accessions resistant to witches' broom disease based on RAPD and pedigree data. Bragantia, v.64, p.361-368, 2005.

SAS INSTITUTE. SAS/STAT: user's guide: release 6.03. Cary: SAS Institute, 1988. 1028p.
SOUNIGO, O.; UMAHARAN, R.; CHRISTOPHER, Y.; SANKAR, A.; RAMDAHIN, S. Assessing the genetic diversity in the International Cocoa Genebank, Trinidad (ICG, T) using isozyme electrophoresis and RAPD. Genetic Resources and Crop Evolution, v.52, p.1111-1120, 2005.

WILLIAMS, J.G.K.; KUBELIK, A.R.; LIVAK, K.J.; RAFALSKI, J.A.; TINGEY, S.V. DNA polymorphisms amplified by arbitrary primers are useful as genetic markers. Nucleic Acids Research, v.18, p.6531-6535, 1990.

YAMADA, M.M.; FALEIRO, F.G.; LOPES, U.V.; BAHIA, R.C.; PIRES, J.L.; GOMES, L.M.C.; MELO, G.R.P. Genetic variability in cultivated cacao populations in Bahia, Brazil, detected by isozymes and RAPD markers. Crop Breeding and Applied Biotechnology, v.1, p.377-384, 2001.

YAMADA, M.M.; FLORES, A.B.; FALEIRO, F.G.; MELO, G.R.P.; MACEDO, M.M.; LOPES, U.V.; CORRÊA, R.X.; SANTOS, R.F. Identificação e variabilidade genética de acessos de cacaueiros autocompatíveis selecionados para resistência à vassoura-de-bruxa em fazendas produtoras. Agrotrópica, v.17, p.17-22, 2005.

YAMADA, M.M.; LOPES, U.V. Paternity analysis of cacao trees selected for resistance to witches' broom in plantations of Bahia, Brazil. Agrotrópica, v.11, p.83-88, 1999.

YAMADA, M.M.; PIRES, J.L.; LOPES, U.V.; FLORES, A.B.; MELO, G.R.P. Diversidade e origem de seleções de cacau (Theobroma cacao L.) feitas em fazendas para resistência à vassoura-de-bruxa. In: CONGRESSO BRASILEIRO DE MELHORAMENTO DE PLANTAS, 3., 2003, Porto Seguro. Anais. Porto Seguro: Sociedade Brasileira de Melhoramento de Plantas, 2003. (CD-ROOM). 